\title{
Analysis of Economic Indicators of Complex Production Processes
}

\author{
Korneev A.M.*, Abdullakh L.S. * \\ * Lipetsk state technical University, Russia
}

\begin{abstract}
The article describes the methodology for describing the economic indicators of management effectiveness and decision-making under conditions of complex multi-stage productions. The algorithm and the forecast model of the need for production resources are presented, that allow providing more complete information on costs and help in pricing for various products, significantly reducing the response time to economic and technological situation changes. Characteristics of technology parameters are linked to a multi-stage production process. As the semi-finished product passes through the processing stages, the values of the technological factors are fixed. Methods for estimating the influence of parameters of complex spatially-distributed systems on costs are presented. Important elements of costs that affect the product value are determined. Detailing the cost elements for the technological operations under study is carried out, the boundaries, where the largest amount of resources is spent, are determined.
\end{abstract}

Keywords: methodology, economic indicators, complex production processes, technology parameters.

\section{Introduction}

The methodology of calculating costs for the products produced in metallurgical practice is based on enlarged indicators of resource consumption. These indicators are calculated on the basis of actual costs, and then averaged over the enterprise assortment. In this methodology, we could see the tendency to average the enterprises efficiency in the sector, and sizes/ profiles - according to the assortment. Under this approach, it is difficult to estimate the real costs of resources (feedstock, equipment, materials, energy, etc.) for products of different types and qualities, to reasonably distribute these costs for individual technological operations and, consequently, to work on resource efficiency and improving the product competitiveness. The proposed methodology based on the calculation methods that allow to predict the resource costs for processing by various technological schemes. Creation of a data set, their reorganization, control, correction, addition and removal of records, as well as searching for the necessary information on the given characteristics, changing its structure and location, ordering by the specified characteristics, mapping to various media are carried out by separate blocks.

The block of the actual manufacture account is intended for the analysis of manufacture volumes on standard sizes and marks of steel for the researched period of time. The analysis is performed for individual processing and aggregates. If necessary, consolidated statements are issued.

The analysis of themain resource expenditure the on aggregates is carried out by the unit for recording the actual consumption of raw materials, energy resources and materials in the manufacture of certain types of products. Important costs elements that affect the product value are determined. At the next stage, the detailing of cost elements for the technological operations under study is performed, there were set the boundarieswhere the largest amount of resources is spent. All costs are related to technological factors (time, speed, etc.).

\section{Research Method}

The basis of the block is the matrix of resource intensity relative coefficients:

$K_{g_{l_{s}}}(s, t)=\frac{z^{*}\left(s, l_{s}, g, t\right)}{z^{*}\left(s, l_{s}^{0}, g_{l_{s}^{0}}, t\right)}$

Where $g_{l_{s}}$ istheresource (spending),$l_{s}$ istheproducttype, $z^{*}\left(s, l_{s}, g_{l_{s}}, t\right) z_{i j}$-thecalculatedresourceconsumption $g_{l_{s}}$ for 1tofproducttype $l_{s} ; z^{*}\left(s, l_{s}^{0}, g_{l_{s}^{0}, t}\right)^{z_{0 j}}$ - the calculated resource consumption $g_{l_{s}}$ for 1 tof product type $l_{s}^{0}$, used as a basis (adapts to a specific technology). With a known production plan, the total resource costs, differentiated by steel marks, sizes and production volumes, are determined. Need for all resources:

$z\left(s, g_{s}, t\right)=\sum_{\mathbb{I}_{s}=1}^{L_{s}} K_{g_{l_{s}}}(s, t) \cdot z^{*}\left(s, l_{g}, g_{l_{x}}, t\right) \cdot{\overline{X_{1}}}_{1}\left(s, l_{g}, t\right)$

where $z\left(s, g_{s}, t\right)$ is the need for the resource $j ; m$ - the number of products in the production plan in question; $\bar{X}_{1}\left(s, l_{s}, t\right)$ is the output of products of the type $l_{s}$. It is necessary to calculate themain energy resourcesconsumption for each steel and product type separately. This will make it possible to implement a forecast of resource consumption when the technological mode changes. For all cost elements, a specific technological quantity or a set of them is assigned.

Technological factors are determined for all steel marks. To compare their values we need a scaling factor to be determined. Each 
type of costs used on the aggregate for the entire assortment and the calculated total value of the technological factor under research are correlated by a dependence of this kind of formula:

$z\left(s, l_{g}, t\right)=K_{g_{x}} \cdot X_{1}^{*}\left(s, \sum k_{l_{z}}, t\right)$

where $-z\left(s, g_{s}, t\right)$ is the total value of $g_{s}$-th kind of costs for the full assortment, on aggregate $\mathrm{s}$ for a period of time t. Where $g_{s}=1_{s}, \ldots, G_{s}$ are the resource types used on the s-th aggregate, $G_{s}$ is the amount of resources.

$X_{1}^{*}\left(s, \sum k_{l_{s}}, t\right)$ is the total value of the technological factor understudy. $K_{g_{s}}$ - is a scale factor that represents the fraction of the $g_{s}$-th kind of costs, correlated with thetechnological factor unit. The total value of the technological factor under study $X_{1}^{*}\left(s, \sum k_{l_{s}}, t\right)$ is formed as a sum of individual components related to different types of production $l_{s}$. Hence:

$z\left(s, g_{s}, t\right)=K_{g_{x}} \sum_{\mathbb{l}_{s}=1}^{L_{x}} X_{1}^{*}\left(s, l_{g}, k_{l_{s}}, t\right) \cdot \bar{X}_{1}\left(s, l_{g}, t\right)$

Where $\quad X_{1}^{*}\left(s, \sum k_{l_{s}}, t\right)=\sum_{l_{g}=1}^{L_{s}} X_{1}^{s}\left(s, l_{g}, k_{l_{g}}, t\right)$, $\bar{X}_{1}\left(s, l_{s}, t\right)$ is the mass of each product. $x_{1}^{*}\left(s, l_{s}, k_{l s}, t\right)$ - the "consumption" of the technological factor for unit $l_{s}$-thproduct type. If $X_{\min }^{*}\left(s_{y} l_{g}, k_{l_{s}}, t\right)$ - the minimum value (scalevalue) of the technological factor of the whole assortment under analysis, then:

$z\left(s, g_{s}, t\right)=K_{g_{s}} \sum_{l_{s}=1}^{L_{s}} X_{1}^{*}\left(s, l_{g}, k_{l_{s}}, t\right) * \bar{R}_{1}\left(s, l_{g_{s}}, t\right)=K_{g_{s}} \sum_{l_{s}=1}^{L_{s}} X_{\min }^{*}\left(s, l_{g}, k_{l_{s}}, t\right) * r\left(s l_{l^{\prime}}, k_{l_{s}}, t\right) * X_{1}\left(s, l_{g}, t\right)$

The coefficient of proportionality $r\left(s l_{g}, k_{l_{s}}, t\right)$ gives an indication of the resources excess on the production of the $\mathrm{i}$-thproduct type in relation to the base species with $X_{\min }^{8}\left(s, l_{s}, k_{l s}, t\right)$. These coefficients are determined for all cost elements for each product type. The scaling type has $r\left(s l_{s}, k_{l_{s}}, t\right)=1$. Therefore:

$$
X_{\min }^{*}\left(s_{x} l_{g}, k_{l g}, t\right)=\frac{z\left(s_{x} g_{g}, t\right)}{K_{g_{s}} \sum_{\mathbb{l}_{s}=1}^{L_{s}} r\left(s_{s} l_{g}, k_{l_{s},} t\right) * X_{1}\left(s_{x} l_{g}, t\right)}
$$

Consumption of cost elements for the i-thproduct type:

$X_{1}^{*}\left(s, l_{g}, k_{l g}, t\right)=X_{\min }^{*}\left(s_{v} l_{g}, k_{l g}, t\right) * r\left(s l_{g}, k_{l_{s}}, t\right)$

If technological factors are given, then it is possible to determine the costs for any period under study.

The initial data are:

- data set containing information on the production volumes of sold $M$-products;

- technological factors set for all costs of $X^{Z}$;

- a diagonal matrix of certain coefficients of proportionality for all cost elements $K^{Z X}$.

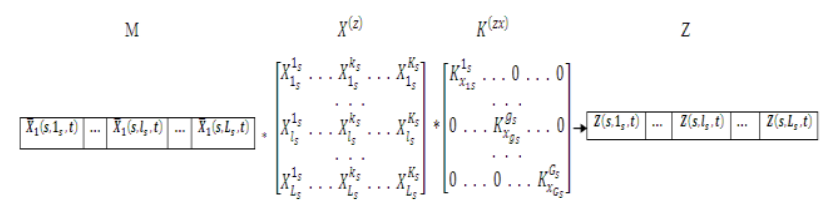

Fig. 4.1: Determination of cost matrix $Z$.

In matrix form: $\quad\left(M * X^{(Z)}\right) * K^{(Z X)}=Z$

To perform a comprehensive assessment of the resource consumption dependence on technological factors, it is necessary to form a cost matrix that takes into account the influence of all factors under study (size $(K \times P))$ :

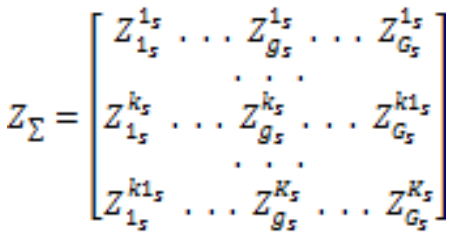

There will be formed a generalized matrix of coefficients of proportionality $\mathrm{K} \Sigma$ for it:

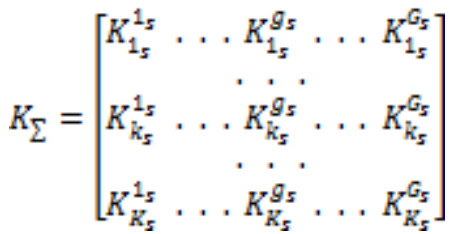

Then we will calculate a matrix that contains the mean values $\bar{X}_{l_{s}}^{k_{s}}$ of the selected process quantities for each type of production $X\left(\operatorname{size}\left(L_{g} \times K_{s}\right)\right)$ :

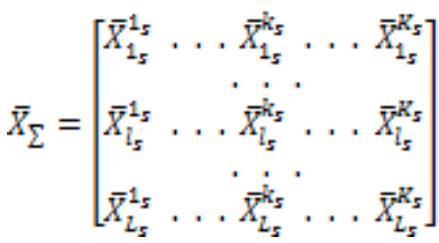

\section{Results and Anslysis}

Based on the aggregated matrices of the coefficients of proportionality $K_{\Sigma_{I}}$ for each of the periodsunder study, it is possible to carry out a forecast of the resource consumption for other periods by all coefficients $K_{\Sigma_{I}}$.

Using the matrix of proportionality factors for the base period $\boldsymbol{K}_{\boldsymbol{\Sigma}}$ $\mathbf{\Sigma}_{\text {study }}$ and the total consumption of technological parameters for the period under study $\operatorname{diag}_{\boldsymbol{g}}\left(\boldsymbol{M} * \boldsymbol{X}_{\Sigma}\right)_{\text {study }}$, it is possible to forecast the resource consumption in the current period by the base coefficients

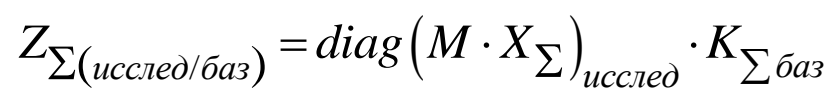

where $Z_{\sum \text { (study/base) }}$ - the matrix of total costs for the analysis month for the base one

$\operatorname{diag}\left(M X_{\Sigma}\right)_{\text {study }}$ - diagonal matrix for the period under study;

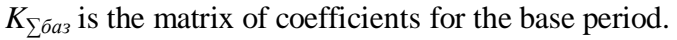

Similarly, forecast matrices are determined for all the i-th periods under study by the coefficients of proportionality of the base $\mathrm{J}$ periods.

$$
z_{\Sigma(t \bar{t})}=\operatorname{diag}\left(M * X_{\Sigma}\right)_{(t)} * K_{\Sigma(t)}
$$

\begin{tabular}{|c|c|c|c|c|c|c|}
\hline \multirow[b]{2}{*}{$\begin{array}{l}\text { Cost forecasts by } \\
\text { the period }\end{array}$} & \multicolumn{5}{|c|}{ Technological parameters } & \multirow{2}{*}{$\begin{array}{l}\text { Real resource } \\
\text { consumption } \\
Z_{R(I)}\end{array}$} \\
\hline & $X_{I}$ & $X_{2}$ & $X_{3}$ & & $X_{k}$ & \\
\hline 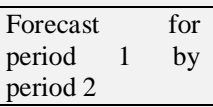 & & & & $Z_{g_{s}}$ & & Z \\
\hline Forecast & & & & & & $Z_{g_{s}}(t)$ \\
\hline
\end{tabular}

The summary table for each cost element has the form (Table 1).

Model of the consumption forecast 


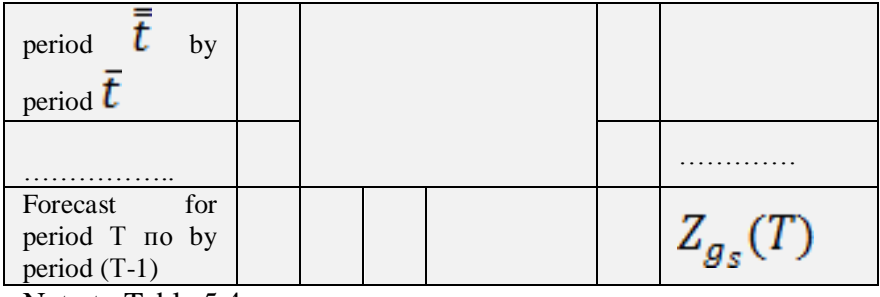

Note to Table 5.4:

$X_{k}-k$ - th is the technological parameter;

$Z_{g_{s}}^{k_{s}}(\bar{t}, \bar{t})$ is t0he forecast value for the $\overline{\bar{t}}_{\text {-th period of the re- }}$ source consumption $g_{s}$ according to $\bar{t}_{p}$-th period of the $k_{s}$ parameter.

To estimate the effect of individual parameters on cost elements, we need to construct the separate forecast matrices for each parameter $k_{s}$ (Table 2$)$.

The forecast matrix of costs $g_{s}$ for factors $k_{s}$ for the periods under study

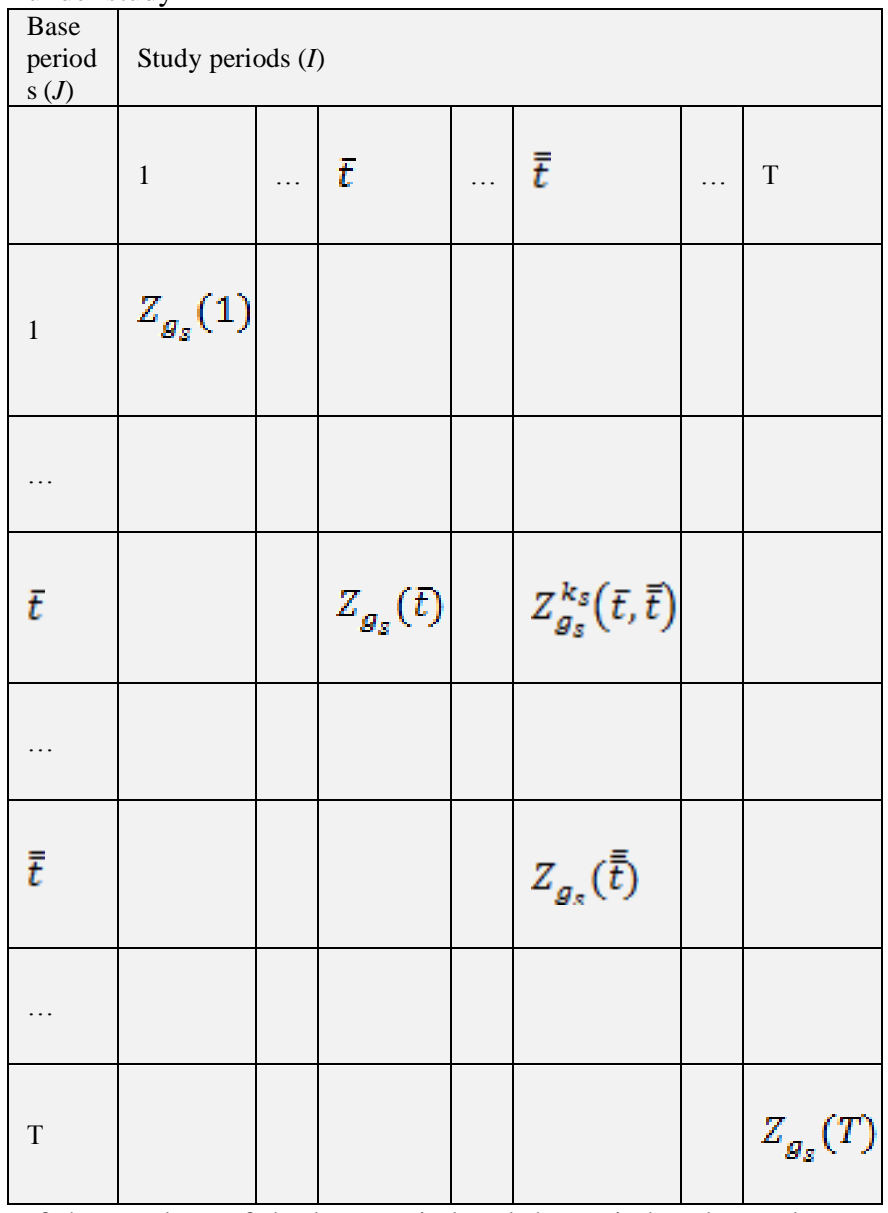

If the numbers of the base period and the period under study are equal $(\bar{t}=\bar{t})$ in Table 5.5, then the actual resource consumption for the period under study $Z_{g_{s}}(\vec{t})$ is indicated instead o $Z_{g_{s}}^{k_{s}}(\bar{t}, \overrightarrow{\bar{t}})$ As a result, we can get average forecasts for individual periods and for the entire study period (for example, a year). The average error of period forecasts for the parameter under study $k_{s}$ :

$\bar{\varepsilon}_{g_{S}}^{k_{s}}=\frac{\sum_{t=1}^{T}\left|\mathrm{z}_{\mathrm{Bg}_{s}}(\mathrm{t})-z_{g_{s}}^{k_{s}}(\bar{t}, \overline{\bar{t}})\right|}{T}$

where $Z_{g_{s}}(\bar{t})$ is the actual resource consumption $g_{s}$ for the period under study $\bar{t}$.

$Z_{g_{s}}^{k_{s}}(\bar{t}, \overline{\bar{t}})$ - projected resource costs $g_{s}$ by factor $k_{s}$ on period $\bar{t}$ according to matrix of base coefficients for the period $\overline{\bar{t}}$
$T$ - number of forecast periods.

\section{Conclusion}

Methods and models for describing economic indicators of management effectiveness and decision-making under conditions of complex multi-stage productions have been developed.

Algorithms and models for forecasting the demand for resources production have been developed, which allow providing more complete information on costs and help in pricing for various product types, significantly reducing the response time to economic and technological situation changes.

Methods for estimating the influence of complex spatiallydistributed systems parameters on costs are presented.

\section{References}

[1] Abdullah L.S, Korneev A.M, Smetannikova T.A. Structural cellhierarchical identification of complex spatially distributed production systems // Proceedings of the 3rd International Academic Conference. 2013, St. Louis, Missouri, USA. C.75-79.

[2] Korneev, A. M. Methods for the identification of cross-cutting technology production of steel products: monograph / Lipetsk state pedagogical University. - Lipetsk: LGU, 2009. - 286 p.

[3] Korneev, A. M. cellular Structural-hierarchical modeling of complex prostranstvenno-distributed systems. - News of higher educational institutions of the Central Chernozem region, 2011, No. 1, pp 62-66.

[4] Kuznetsov, L. A., A. Korneev, M. Automated system of selecting the optimal technology for the production of steel. - Izvestiya vuzov. Ferrous metallurgy, 1994, No. 5, pp. 45-48.

[5] Stratonovich, R. L. Theory of information. - Moscow: Sov. radio, 1975. - 424 p. Korneev, A. M. the Use of information criteria connection input and output variables for the selection of optimal technologies - Izvestiya vuzov. Ferrous metallurgy, 2004, No. 9, p. 48 52.

A. M. Shmyrin, I. A. Sedykh, Identification and Control Algorithms of Functioning for Neighborhood Systems Based on Petri Nets, Automation and Remote Control, 2010, Volume 71, Issue 6, p. 1265 1274.

[6] S.L. Blyumin, A.M. Shmyrin, O.A. Shmyrina. Bilinear Neighborhood Systems. Monograph. Lipetsk, Lipetsk State Technical University Publishers, 2006. 131 p, (in Russian).

[7] A.M. Korneev, L.S.Abdullakh, T.A. Smetannikova, CRITERION FOR ASSESSING THE EFFECTIVENESS OF FUNCTIONING OF COMPLEX SYSTEMS BASED ON THE USE THE AMOUNT OF INFORMATION, International Journal of Applied Engineering Research. 2015. T. 10. № 11. C. 27961-27980. 